\title{
Tele-assistance in chronic respiratory failure patients: a randomised clinical trial
}

\author{
M. Vitacca*, L. Bianchi*, A. Guerra*, C. Fracchia\#, A. Spanevello", \\ B. Balbi ${ }^{+}$and S. Scalvini ${ }^{\S}$
}

ABSTRACT: Chronic respiratory patients requiring oxygen or home mechanical ventilation experience frequent exacerbations and hospitalisations with related costs. Strict monitoring and care have been recommended. The aim of the present study was to primarily evaluate reduction in hospitalisations and, secondly, exacerbations, general practitioner (GP) calls and related costeffectiveness of tele-assistance (TA) for these patients.

A total of 240 patients (101 with chronic obstructive pulmonary disease (COPD)) were randomised to two groups: an intervention group entered a 1-yr TA programme while controls received traditional care.

No anthropometric and clinical differences were found between groups both in baseline and in mortality (18\% for TA, $23 \%$ for controls). Compared with controls, the TA group experienced significantly fewer hospitalisations (-36\%), urgent GP calls (-65\%) and acute exacerbations (-71\%). Only COPD patients, as a separate group, had fewer hospitalisations, emergency room admissions, urgent GP calls or exacerbations. Each patient referred to staff a mean \pm SD $36 \pm 25$ times. After deduction of TA costs, the average overall cost for each patient was $33 \%$ less than that for usual care.

In chronic respiratory failure patients on oxygen or home mechanical ventilation, a nursecentred tele-assistance prevents hospitalisations while it is cost-effective. The chronic obstructive pulmonary disease group seems to have a greater advantage from tele-assistance.

KEYWORDS: Amyotrophic lateral sclerosis, chronic obstructive pulmonary disease, home care mechanical ventilation, telehealth telemedicine

$\mathrm{H}$ ome care for respiratory patients is a complex array of services delivered in an uncontrolled setting in which patients and families are integral members of the healthcare team [1]. Complexity, lack of direct control and acute exacerbations of chronic conditions all probably contribute to the difficulty in organising home care assistance [1]. Among home care programmes, home mechanical ventilation (HMV) has a great prevalence in European countries [2]. Follow-ups have been strictly recommended to be structured and are to be integrated with technology for patients on HMV [3-5] since traditional, nurse-based home followup programmes, if they exist, have limitations relating to: the number of patients that can be included; costs; and logistical problems, such as distance and time needed to reach the patients at their homes. A recent American Thoracic Society statement [1] has emphasised the need of a strict follow-up of these frail patients. In particular, home care should focus on a patient-centred perspective and patient and family satisfaction: reduction of complications resulting from hospitalisation; maintaining an acceptable quality of life; and enabling a comfortable and dignified death have been proposed as major end-points [1] Chronic obstructive pulmonary disease (COPD) seems to be the most problematic chronic disease for all the health systems, with frequent exacerbations, hospitalisations and related costs [6-9]. Various follow-up models to prevent hospitalisations and exacerbations have been proposed: these include self-management $[10,11]$, home care [12] and dedicated chronic care model with or without support via information technologies $[13,14]$. The need to rationalise healthcare costs [15-17] has prompted the development of new technologies for home assistance [18]. The model of telemedicine has recently been tested in different studies [13, 19-22] with the major end-points assessing programme feasibility. However, controlled studies that evaluate the influence of this new technique on outcomes are lacking.
AFFILIATIONS

*Divisione di Pneumologia

${ }^{\S}$ Servizio di Telemedicina,

Fondazione S. Maugeri, IRCCS,

Lumezzane,

\#Divisione di Pneumologia,

Fondazione S. Maugeri, IRCCS,

Montescano

"Divisione di Pneumologia,

Fondazione S. Maugeri, IRCCS,

Cassano delle Murge, and

+Divisione di Pneumologia

Fondazione S. Maugeri, IRCCS

Veruno, Italy.

CORRESPONDENCE

M. Vitacca

Pneumology Division

Fondazione Salvatore Maugeri

Via Mazzini 129

25066

Lumezzane

Italy

Fax: 39308920262

E-mail: mvitacca@fsm.it

Received

January 132008

Accepted after revision:

September 062008

SUPPORT STATEMENT

This study is registered with clinical trial identifier number NCT00563745

STATEMENT OF INTEREST

None declared.

European Respiratory Journal

Print ISSN 0903-1936

Online ISSN 1399-3003 
The primary aim of the present study was to evaluate the reduction in hospitalisations resulting from a tele-assistance (TA) programme based on a continuous $24 \mathrm{~h}$ on-call service and pulse oximetry availability, as compared with the usual outpatient follow-up regimen in patients requiring oxygen therapy or HMV.

Secondary end-points were to test reduction in home exacerbations, emergency room admissions, urgent general practitioner (GP) calls and a possible cost-effectiveness.

\section{METHODS}

The present prospective study was conducted in all patients with chronic respiratory failure (CRF) discharged from the Respiratory Department of Fondazione S. Maugeri Gussago/ Lumezzane (Italy) from April 30, 2004 to March 31, 2007.

The inclusion criteria were: 1) need for HMV, and/or 2) need of long term oxygen therapy (LTOT) and at least one hospitalisation for respiratory illness in the previous year. Exclusion criteria were: 1) illiteracy or no telephone access at home; 2) residence in a nursing home; 3) no caregiver to facilitate telephone contacts; 4) refusal. Of 351 CRF patients, $240(68.3 \%)$ fulfilled the selection criteria and were enrolled in the study (fig. 1). Using a set of computer-generated random numbers in 1:1 ratio patients were assigned to the treatment or control group. After informed consent was obtained, all patients received a pulse oximetry device (Nonin 9500 oximeter; Nonin, Plymouth, MN, USA). In selected cases (severe clinical and pulse oximetric worsening in spite of drug therapy rearrangement, long term oxygen or mechanical ventilation resetting, correct titration of oxygen supply during night and activities of daily living, and suspicion of nocturnal hypoventilation) patients received a pulse oximeter with solid memory card (Nonin 2500 oximeter; Nonin) plus a modem system (30 EM model Medical Botticelli web; Digicom, Cardano al Campo, Italy), which is able to transmit an arterial oxygen saturation measured by pulse oximetry $\left(\mathrm{Sp}, \mathrm{O}_{2}\right)$ trace

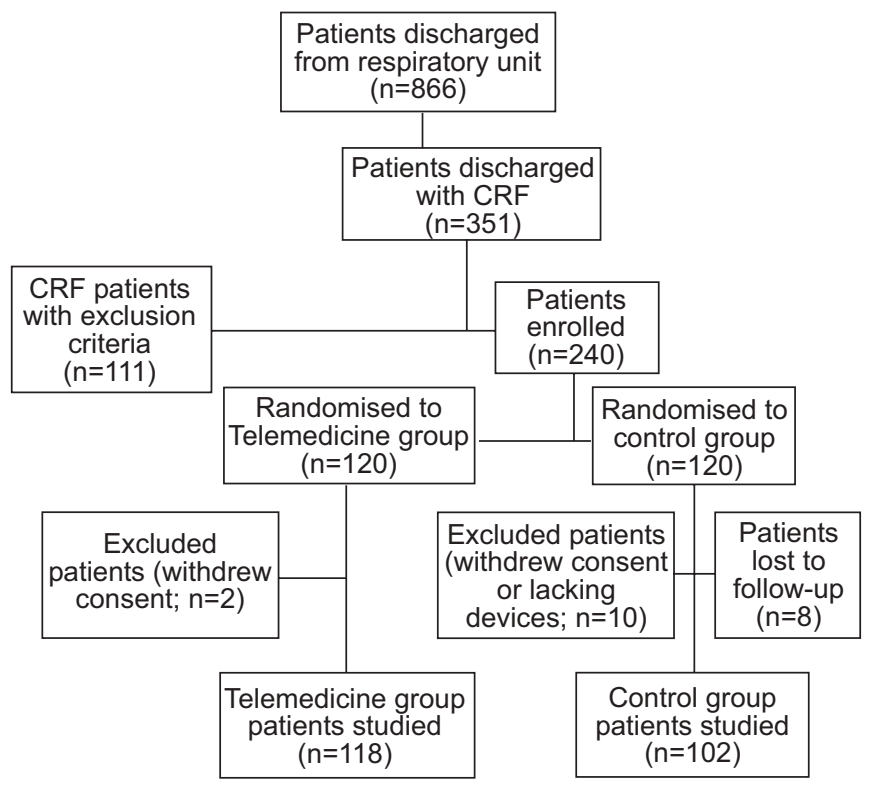

FIGURE 1. Trial profile of the enrolled patients. CRF: chronic respiratory failure. through the home telephone line. When necessary, the trace was sent to a receiving station where a TA nurse was available for $40 \mathrm{~h}$ per week (08:00 $\mathrm{h}$ to $16: 00 \mathrm{~h}, 5$ days per week) to provide a real-time tele-consultation. The TA nurse followed patients in the present study and another 80-100 patients enrolled in the same TA programme of the hospital. Unscheduled calls were transferred to the on-duty pulmonologist who provided a consultation. The call centre was able to receive data $24 \mathrm{~h}$ per day concerning patients' needs or questions and, when needed, the pulmonologist on duty was contacted. TA group patients had no scheduled outpatient visits with the pulmonologist. Scheduled appointment telemonitoring and ad hoc appointment tele-assistance were conducted as decribed in detail elsewhere [22].

Patients in the usual care group were evaluated by the physician before discharge. Follow-up outpatient visits aimed at assessing compliance to therapy, HMV and/or LTOT were scheduled every 3 months according to the usual procedures of the study centre. The discharge plan did not include home nurse visits.

\section{Measurements and instruments}

At the first contact (baseline) the nurse tutor administered a clinical scoring system to TA patients, Respicard ${ }^{\circledR}$ [23]; this was used during the follow-up telephone contacts to assess any clinical variation. The system is described in detail in Appendix 1. If there was a score variation of $\geqslant 3$ points from baseline, the nurse was instructed to contact the pulmonologist for consultation. Baseline anthropometric and clinical data for all patients were recorded: pre-morbidity lifestyle score (ranging from 0 : employed with maximal level of autonomy; to 4: bedridden) [24]; respiratory function; arterial blood gases; and number of comorbidities. TA staff calls and number of pulse oximetry recordings were registered in the electronic database. During the study, the following data were recorded: mortality, exacerbations requiring antibiotics and/or steroids, days free from the first exacerbation, hospitalisations, days free from the first hospitalisation, intensive care unit (ICU) admissions, emergency room admissions, days free from the first emergency room admission, urgent GP calls and days free from the first GP call. Details of the call centre are reported elsewhere [22]. Fixed and variable call centre costs, as well as nurse and medical second opinion costs, are reported elsewhere [25]. Pulse oximetry device costs (table 1) were calculated as the hire costs for the study duration or by dividing the total costs by the number of patients enrolled in 3 yrs. The total TA costs were expressed as monthly cost and mean cost per patient. Health system costs were calculated by multiplying the number of events (stay or performances) for the unit cost per event using Medicare diagnosis-related group reimbursement values. Costs for drugs and transportation were directly calculated using information about market prices.

The Fondazione S. Maugeri IRCCS Ethics Committee approved the study according to recommendations contained in the Declaration of Helsinki and all patients gave their written informed consent to participate in the protocol.

\section{Data analysis}

An $80 \%$ power to detect a reduction of 9 points on the average value of the monthly hospitalisation proportion was estimated 


\section{TABLE 1 Costs for tele-assistance (TA) activation and healthcare service (HCS) costs}

\begin{tabular}{|c|c|c|c|c|c|c|}
\hline & \multirow{2}{*}{$\begin{array}{c}\text { Cost per unit } \\
€\end{array}$} & \multirow[t]{2}{*}{ Factor to multiply } & \multicolumn{2}{|c|}{ All patients } & \multicolumn{2}{|c|}{ COPD patients } \\
\hline & & & $\mathrm{TA} €$ & Control $€$ & $\mathrm{TA} €$ & Control $€$ \\
\hline \multicolumn{7}{|l|}{ Telemedicine costs } \\
\hline Call centre costs ${ }^{\#}$ & 20 & Number of calls per patient & $716 \pm 504$ & 0 & $821 \pm 537$ & 0 \\
\hline Pulsed saturimetric device & 127 per patient & 1 for patient & 127 & 0 & 127 & 0 \\
\hline \multicolumn{7}{|c|}{ TA costs with pulsed saturimetric device } \\
\hline Total & & & $843 \pm 504$ & 0 & $948 \pm 537$ & 0 \\
\hline Monthly & & & $86 \pm 56$ & & $95 \pm 61$ & \\
\hline \multicolumn{7}{|c|}{$\begin{array}{l}\text { TA costs with trend pulsed saturimetric } \\
\text { device }\end{array}$} \\
\hline Total & & & $903 \pm 504$ & 0 & $1008 \pm 537$ & 0 \\
\hline ER admissions & 62 & Number & $38 \pm 84$ & $57 \pm 87$ & $39 \pm 63$ & $80 \pm 105$ \\
\hline Hospitalisation in $\mathrm{ICU}^{\S}$ & According to DRG & Number & $3998 \pm 15114$ & $7509 \pm 22906$ & $3842 \pm 15082$ & $15365 \pm 31897$ \\
\hline Outpatient visit & 32 & Number & $4 \pm 12$ & $104 \pm 39$ & $6 \pm 14$ & $98 \pm 41$ \\
\hline Urgent GP visit & 30 & Number & $20 \pm 41$ & $48 \pm 80$ & $23 \pm 51$ & $72 \pm 110$ \\
\hline Antibiotics use (12 days) & 55 & Number & $86 \pm 109$ & $203 \pm 184$ & $108 \pm 129$ & $273 \pm 196$ \\
\hline Steroids use (14 days) & 6 & Number & $3 \pm 7$ & $16 \pm 18$ & $5 \pm 9$ & $24 \pm 21$ \\
\hline Home nurse visits & 20 & Number & $148 \pm 328$ & $178 \pm 367$ & $108 \pm 282$ & $82 \pm 253$ \\
\hline \multicolumn{7}{|l|}{ Private costs } \\
\hline Transportation & 0.23 per $\mathrm{km}$ & Distance km & $0.8 \pm 3$ & $27 \pm 25$ & $1.2 \pm 3.2$ & $21 \pm 7$ \\
\hline Total HCS costs & & & $8907 \pm 17580$ & $14728 \pm 28694$ & $9886 \pm 17534$ & $24743 \pm 39484$ \\
\hline
\end{tabular}

COPD: chronic obstructive pulmonary disease; RW: respiratory ward; ER: emergency room; ICU: intensive care unit; GP: general practitioner; DRG: diagnosis-related group. "\#: fixed costs included equipment purchase and installation, and installation of telecommunication lines; variable costs included monthly line charges, maintenance costs, nurse and pulmonologist second opinion on duty calls. ": costs on hire. ${ }^{+}:$costs calculated dividing the total costs of the devices by the number of patients enrolled in 3 yrs; details of costs are described previously [25]. s: 14 in TA group and 16 in control group.

between the two groups. The level of significance ( $\alpha$ level or type-I error level) is equal to 0.05 . The estimated number of patients to be enrolled in each group was 100. Results are expressed as mean $\pm \mathrm{SD}$, median (range) or percentages, where appropriate. Descriptive data are shown as mean \pm SD. An unpaired two-sample t-test was used to assess differences in baseline characteristics between the TA and control groups, and Mann-Whitney U-test was employed for nonparametric data. Frequency distributions were analysed with Chi-squared test. In estimating resources, patients in the TA group were divided into two subgroups according to frequency of GP calls and the median was applied as a cut-off value. Kaplan-Meier survival analysis with log-rank statistics adjusted for the use of HMV was employed to estimate time-to-event models. The same statistical model was applied after stratification according to diagnosis. Level of statistical significance was set at 0.05 .

\section{RESULTS}

Among 351 patients with CRF (fig. 1), 111 patients were excluded because of reduced cognitive status $(n=43)$, insufficient family cultural requisites and lack of home prerequisite for TA $(n=34)$, or refusal $(n=34)$. The diagnosis of excluded patients was: COPD $(56 \%)$, restrictive lung disease $(15 \%)$, neuromuscular diseases (NM; 10\%), amyotrophic lateral sclerosis (ALS; 9\%) and other (10\%). Baseline characteristics of TA patients and controls are shown in table 2. No differences were found between groups for all the anthropometric, clinical and functional parameters at baseline, both as a whole group and after stratification according to diagnosis. Among 57 COPD patients, 21 used noninvasive ventilation (NIV) and eight were tracheostomised under mechanical ventilation, while in the group of 61 patients with other diagnosis, 29 used NIV and 18 invasive mechanical ventilation. Out of 4,227 TA calls, median (range) 2.42 (12.0) calls per patient per month were scheduled by the call centre staff while 0.5 (10.5) calls per patient per month were requested by the patients. The median (range) numbers of pulmonologist second opinions, therapy modifications and the pulse oximetry requests were $0.17(4.5), 0.17(2.7)$ and 0.33 (6) per patient per month, respectively. Patients' and caregivers' problems were resolved by nurses in $63 \%$ of cases, and by nurse and pulmonologist together in $37 \%$ of cases. The median value of telephone calls per month was 3.15. The TA team received $4.2 \pm 3.5$ reports per month of pulse oximeter data (range $0-18$ ); $36 \%$ of these were desaturation events $\left(\mathrm{Sp}, \mathrm{O}_{2}<90 \%\right)$. Recording of a diurnal or nocturnal trend was prescribed $0.78 \pm 1$ times 


\begin{tabular}{|c|c|c|c|}
\hline & TA & Controls & p-value \\
\hline Patients n & 118 & 102 & \\
\hline Age yrs & $61.2 \pm 17.6$ & $61.1 \pm 17.4$ & NS \\
\hline \multicolumn{4}{|l|}{ Sex } \\
\hline Males & 75 (64) & 74 (72) & \\
\hline Females & $43(36)$ & $28(28)$ & NS \\
\hline \multicolumn{4}{|l|}{ Diagnosis } \\
\hline COPD & $57(48)$ & $44(43)$ & NS \\
\hline Restrictive & $14(12)$ & $14(14)$ & \\
\hline NM & $24(20)$ & $26(25.5)$ & \\
\hline ALS & $12(10.2)$ & $10(9.8)$ & \\
\hline Other & $11(9.3)$ & $8(7.9)$ & \\
\hline Ex-smokers & $55(47)$ & $43(42)$ & NS \\
\hline Current smokers & $7(6)$ & $9(9)$ & \\
\hline Symptoms yrs & $9.5 \pm 9.3$ & $10.3 \pm 8.9$ & NS \\
\hline Patients under NMV & $50(42)$ & $52(51)$ & NS \\
\hline Patients under IMV & $26(22)$ & $21(21)$ & NS \\
\hline Patients under SB without MV & $42(36)$ & $29(28)$ & NS \\
\hline HMV yrs & $2.1 \pm 1.8$ & $1.9 \pm 2.0$ & NS \\
\hline Patients on LTOT & $75(64)$ & $63(62)$ & NS \\
\hline LTOT yrs & $4.1 \pm 3.1$ & $4 \pm 3.2$ & NS \\
\hline FEV $_{1}^{\#} \%$ pred & $39 \pm 23$ & $34 \pm 16$ & NS \\
\hline vc \% pred & $49 \pm 26$ & $44 \pm 18$ & NS \\
\hline $\mathrm{Pa}_{1} \mathrm{O}_{2}^{+} \mathbf{m m H g}$ & $65 \pm 14$ & $63 \pm 14$ & NS \\
\hline $\mathbf{P a}_{1} \mathrm{CO}_{2}^{+} \mathbf{~ m m H g}$ & $46 \pm 8$ & $47 \pm 9$ & NS \\
\hline $\mathrm{pH}^{+}$ & $7.40 \pm 0.38$ & $7.40 \pm 0.40$ & NS \\
\hline MIP $^{\S} \%$ pred & $42 \pm 30$ & $38 \pm 15$ & NS \\
\hline MEP $^{f} \%$ pred & $39 \pm 24$ & $41 \pm 19$ & NS \\
\hline Comorbidities & $1.69 \pm 1.4$ & $1.57 \pm 1.24$ & NS \\
\hline PLS & $2.50 \pm 0.94$ & $2.45 \pm 0.86$ & NS \\
\hline
\end{tabular}

Data are presented as $n(\%)$ or mean $\pm \mathrm{SD}$, unless otherwise stated. TA: teleassistance; COPD: chronic obstructive pulmonary disease; NM: neuromuscular diseases; ALS: amyotrophic lateral sclerosis; NMV: noninvasive mechanical ventilation; IMV: invasive mechanical ventilation; SB: spontaneous breathing; MV: mechanical ventilation; HMV: home mechanical ventilation; LTOT: longterm oxygen therapy; FEV1: forced expiratory volume in one second; \% pred: \% predicted; $\mathrm{VC}$ : vital capacity; $\mathrm{Pa}, \mathrm{O}_{2}$ : arterial oxygen tension; $\mathrm{Pa}_{\mathrm{a}} \mathrm{CO}_{2}$ : carbon dioxide arterial tension; MIP: maximal inspiratory pressure; MEP: maximal expiratory pressure; PLS pre-morbidity life score [24]; NS: nonsignificant. ${ }^{*}$ : available for 92 patients in TA group and 73 in controls; ": available for 79 patients in TA group and 70 in controls; ${ }^{+}$: measured in room air and available for 85 patients in TA group and 78 in controls; 's: available for 61 patients in TA group and in 59 controls; ${ }^{f}$ : available for 59 patients in TA group and in 57 controls.

per month; in $40 \%$ of these cases, $\mathrm{Sp}_{\mathrm{p}} \mathrm{O}_{2}$ was $<90 \%$ for $>30 \%$ of the recording time. Desaturation events served as a main criterion for oxygen supply changing. During the TA followup, the oxygen supply was maintained in 79 patients, increased in 27 and reduced in 12 . Out of 76 ventilated patients, $55(72 \%)$ requested at least one call owing to trouble with the mechanical ventilation due to insufficient patient compliance, ventilator damage or difficult interaction between patient and machine. The COPD patients, when compared with others, and tracheostomised patients, when compared to
NIV users, were the groups who requested more assistance for ventilation (65.5 versus $42.5 \%$ and 65 versus $44 \%$, respectively). The Respicard score was recorded during any nurse call contact. The average time spent by the nurse to administer it was $4 \pm 3 \mathrm{~min}$. In $57(48 \%)$ out of 118 patients, the Respicard value worsened at least once during the study. Patients with a worsened clinical score compared with patients with unchanged score had a higher number of hospitalisations $(\mathrm{p}<0.04)$, urgent GP visits $(\mathrm{p}<0.04)$ and home acute exacerbations $(p<0.0001)$. The number of hospitalisations per month was significantly $(\mathrm{p}<0.01)$ fewer in the TA group $(0.14 \pm 0.21)$ when compared with controls $(0.22 \pm 0.24)$. In the control group more patients $(\mathrm{p}<0.02)$ had more than two hospital admissions during the study period, whereas in the TA group more patients were free from hospitalisation. The subgroup of COPD patients showed similar data to the whole group with fewer hospital admissions per month in the TA group $(0.17 \pm 0.23)$ compared with controls $(0.30 \pm 0.30 ; \mathrm{p}<0.019)$. Figure $2 \mathrm{a}$ shows that the probability to remain free from hospitalisation for the whole group $(p=0.004)$ was significantly higher for TA than controls. Patients in the TA group were more likely to remain free from an acute exacerbations (fig. 3a) than controls $(p<0.0001)$. Moreover, the mean number of exacerbations per month was significantly $(p<0.0001)$ higher in controls than in the TA group $(0.78 \pm 0.77$ and $0.23 \pm 0.38$, respectively). The total number per month of urgent GP calls was more frequent in controls than in the TA group $(0.22 \pm 0.34$ versus $0.07 \pm 0.17$, respectively; $\mathrm{p}<0.002$ ); patients in the TA group, compared with controls, showed a higher probability of avoiding further GP urgent calls, after the first (fig. 3c; $p=0.0018$ ). The number of patients who made more than one urgent call was higher in the control group than in the TA group $(\mathrm{p}<0.002)$, whereas the number of patients free from GP request was higher in the TA group than in controls. The number of emergency room admissions per month was not significantly different between the two groups $(0.07 \pm 0.20$ and $0.10 \pm 0.17$ for TA group and controls, respectively) while the probability to avoid further emergency room admissions was higher in the TA group $(p=0.0012)$ than in controls (fig. 3e). Mortality was higher but not statistically different in controls (23 deaths, 23\%) compared with the TA group (21 deaths, 18\%; $\mathrm{p}=0.241)$. Causes of death were acute respiratory failure (10 and 12 in TA group and controls, respectively), multiple organ failure (five and seven, respectively), pulmonary embolism (three and two, respectively) and heart attack (three and two, respectively). A total of 16 out of 21 TA patients and 11 out of 23 controls died in hospital. After stratification of patients according to diagnosis, only COPD patients in the TA group (57 subjects) experienced fewer hospitalisations (fig 3; $\mathrm{p}=0.018)$ and had higher probability of avoiding hospitalisation $(p=0.012)$ than controls (44 subjects; fig. $2 b)$. Likewise, only COPD patients in the TA group $(\mathrm{p}<0.0001)$ showed a significantly higher probability of remaining free from acute exacerbations (fig. 3b), from further urgent GP call after the first (fig. $3 \mathrm{~d} ; \mathrm{p}=0.013$ ) and from further emergency room admission (fig. 3f; $p=0003$ ). Mortality rate did not differ between groups even after stratification according to diagnosis ( $p=0.148$ in COPD subgroup). Table 1 shows detailed costs for TA activation and healthcare services during the whole study period for all patients and for the COPD subgroups. TA costs consisted mainly of fixed costs based on the number of calls. 

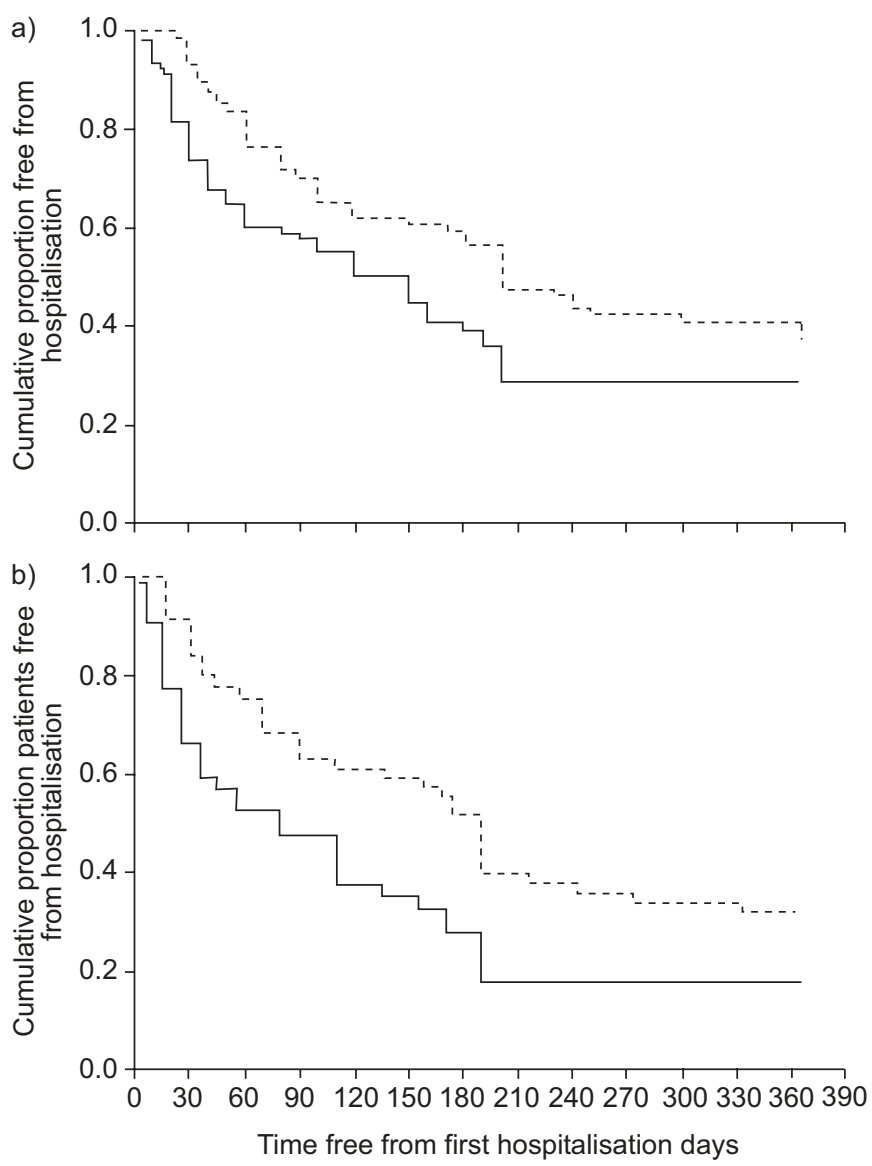

FIGURE 2. Comparison between studied groups for probability to be free from exacerbations. - . - - : tele-assistance group; —_: controls. a) All patients $(p=0.004)$ and $b)$ chronic obstructive pulmonary disease patients $(p=0.012)$.

Savings in healthcare services costs were mainly due to the number of hospitalisations prevented in the TA group. It is noteworthy that a relatively small sample of 30 patients (14 in TA group and 16 in the control group) needing ICU admission accounted for almost $50 \%$ of the total costs of hospitalisation in each group. Deducting costs for the TA programme, the average overall cost per TA patient as a whole group was 33\% less than that for controls, and for COPD patients the cost per TA patient was more than $50 \%$ cheaper than for the control group.

\section{DISCUSSION}

The present study shows that a TA programme is effective in preventing hospitalisations, home acute exacerbations and urgent GP calls, and may be cost-effective in severe CRF patients needing home oxygen therapy and/or HMV. The COPD group seems to take greater advantage from TA.

A general consensus on which type of follow-up programme can achieve optimal control in the management of chronic respiratory diseases is still lacking. A recent review demonstrated that patients with COPD who received interventions with two or more chronic care models had fewer unscheduled/emergency centre visits, fewer hospitalisations, and minor hospital length of stay compared with the control group [14]. According to another recent survey, modern technologies of information and communication have been recommended for HMV patients, in order to improve information exchanging and monitoring among different people involved [4]. In this respect, it should be first questioned whether a TA programme can also be effective in severe patients on LTOT and HMV. Surprisingly, few studies have been published on telemedicine in the respiratory field and none of them reached a clear-cut demonstration of the advantages (if any) of telemedicine over other follow-up programmes for the improved management of these frail patients. Indeed, previous studies have focused on COPD patients [13, 19-21] and on LTOT [26, 27], and addressed the potential impact and benefits of telemedicine in improving quality of life, patients' adherence to treatment and mortality rates, and in reducing healthcare costs, home visits by nurses and costs for acute relapse and emergencies $[13,19-21,26,27]$.

In line with CASAS et al. [13] and MAIOLO et al. [26], the present study confirms that an integrated multidisciplinary monitoring and care with the aid of information technologies can reduce hospitalisations by $\sim 36 \%$, urgent GP calls by $65 \%$ and home relapses by $71 \%$, even in more severe patients. According to the primary end-point (reduction of hospitalisations) the present study also confirms that patients affected with COPD seem to take a greater advantage from TA. Patients affected with other diseases (such as NM or ALS) might also benefit from TA, especially when linked to direct home care assistance; future goals should include patient and family satisfaction, maintainance of an acceptable quality of life and a dignified death at home. In these patients, cost reduction could become a collateral benefit instead of a primary goal for TA and home healthcare.

The current authors confirm the key role of nurses as a specialised figure able to educate patients and their families/ caregivers before discharge, to screen all requests and to coordinate all actors involved in the follow-up. Interestingly, in spite of a great variability among patients, the median value of calls per month was less than four and in $60 \%$ of cases the nurse/tutor alone was able to resolve clinical or logistical problems. Both urgent GP visits and outpatient visits in the current authors' specialised departments were fewer in the TA group than the control group. It can be concluded that a good economical result has been reached without affecting the quality of assistance.

Unlike the study by CASAS et al. [13], in which only $24 \%$ of patients were on LTOT, all patients enrolled in the present study were on LTOT and $>70 \%$ were mechanically ventilated. Another important difference with the studies of CASAS et al. [13] and MAIOLO et al. [26] was the round-the-clock availability of a TA call service, through which a nurse tutor and/or a pulmonologist were available for consultation. Unlike other telemedicine programmes in which periodic phone calls were scheduled every week [26] or every 3 months [13] as "storeand-forward necessity", the service described herein was an interactive online system, as previously described [22]. Moreover, to the current authors' knowledge, the present study is the first conducted on patients with severe disease (which usually represent a great economic burden on the healthcare system), in which a real cost-effectiveness analysis has been performed. The telephone clinical score used by 


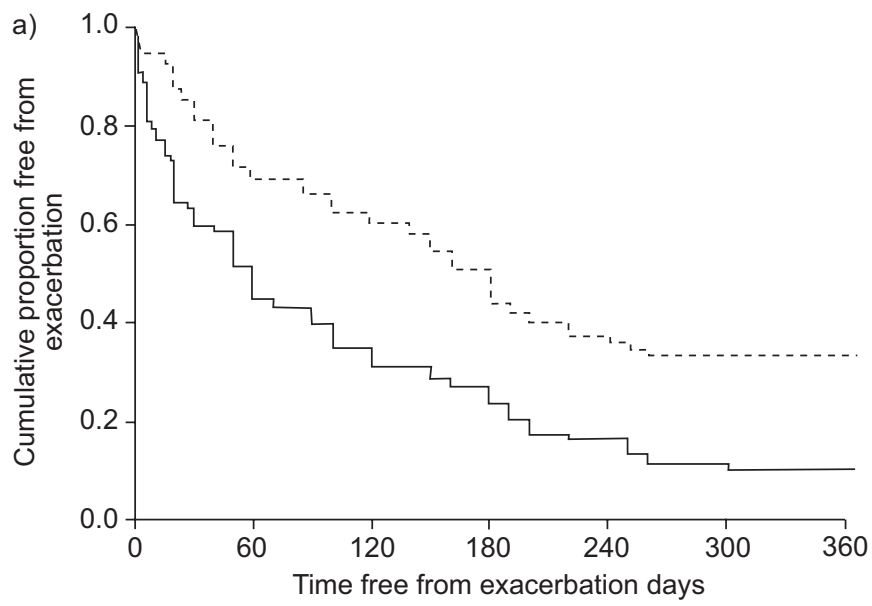

b)

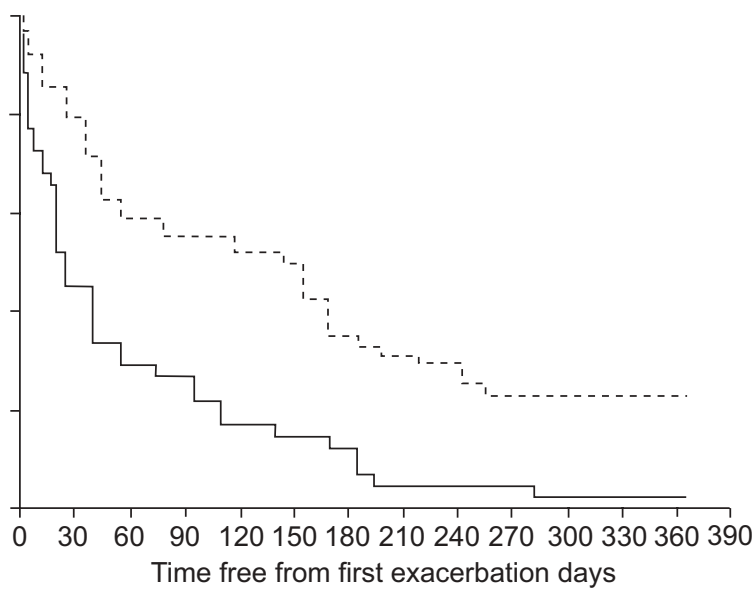

d)
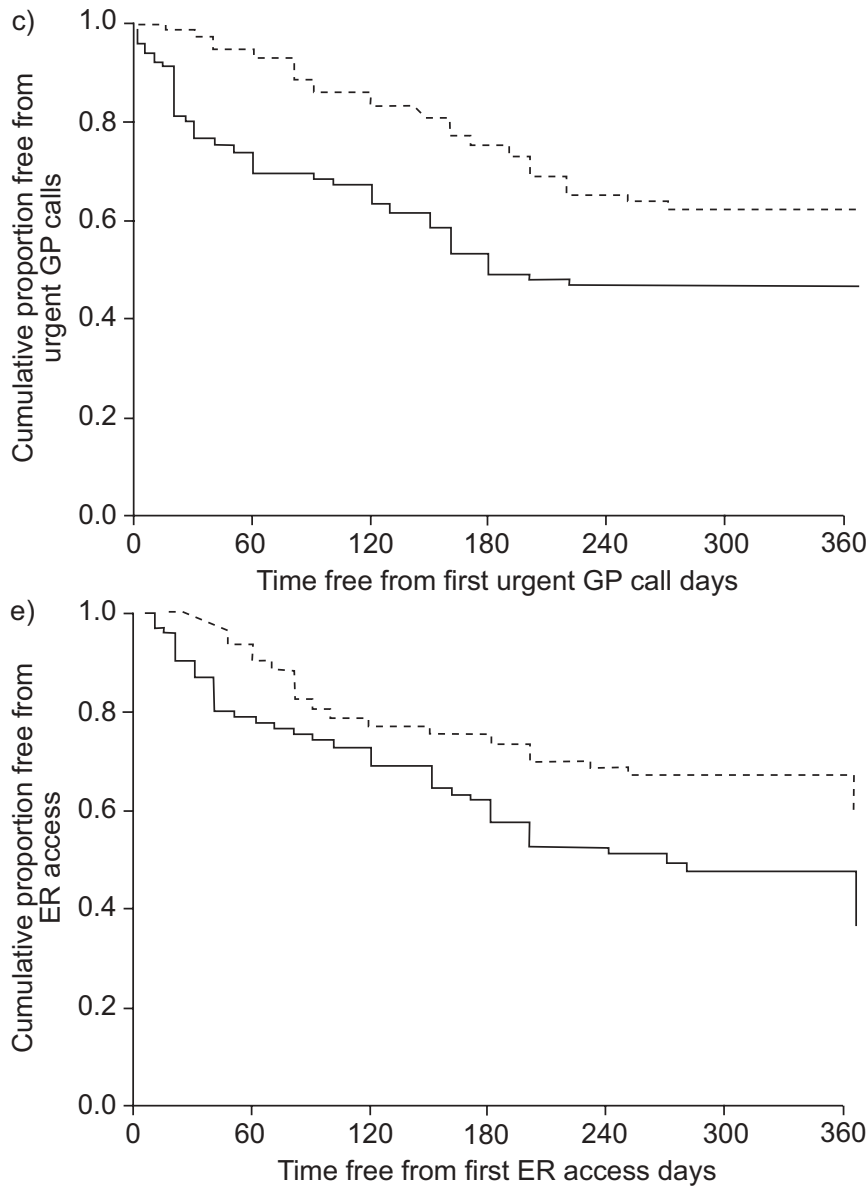
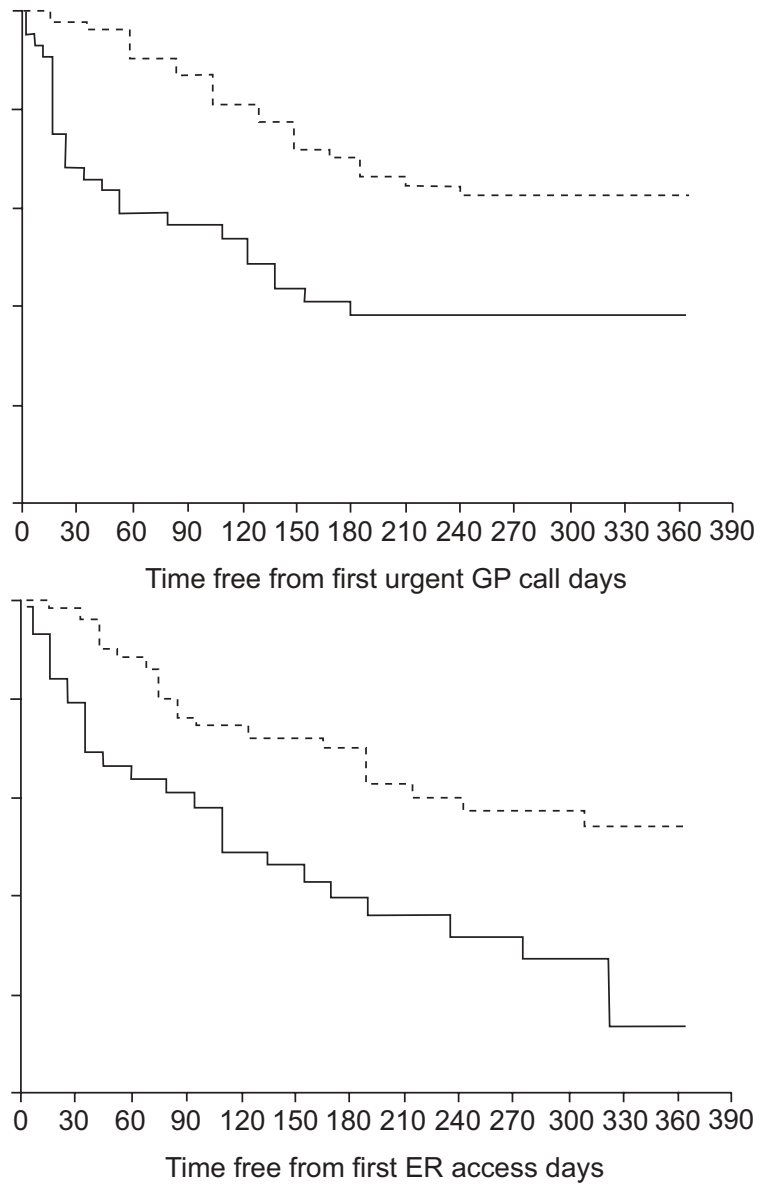

FIGURE 3. Comparison between studied groups (- - - - : tele-assistance group;

: controls) for probability to be free from exacerbations in a) the whole group $(p<0.0001)$ and $b)$ chronic obstructive pulmonary disease (COPD) patients $(p<0.0001)$; from further urgent general practitioner $(G P)$ calls in $c)$ the whole group $(p=0.0018)$ and d) COPD patients $(p=0.013)$; and from further emergency room (ER) access in e) the whole group $(p=0.0012)$ and $f)$ COPD patients ( $p=0.0003)$.

nurses in the study was demonstrated to be simple, repeatable and useful to detect sudden clinical worsening in such severe ventilated patients. A reduction in hospital admissions and indirect costs $[28,29]$ had already been previosusly described when algorithms on computers were used by nurses to follow patients after hospital discharge. Nonetheless, the current authors' belief is that long-term management of chronic patients can be effective only with an interdisciplinary team. The reduction in hospital admissions observed in the present study in the TA programme may have also been favoured by the prompt availability and use of the $\mathrm{Sp}, \mathrm{O}_{2}$ device, which has provided important data for staff decisions about diagnosis of hypoxaemia and oxygen and/or mechanical ventilation prescription.

Although, on the one hand, the miscellaneous diagnosis of the sample may constitute a limitation of the study, on the other hand the authors are confident that the strength of the study lies 
in its radically different point of view, i.e. considering the burden of assistance as the primary requisite to include a patient in a TA programme, independent of the underlyng diagnosis. In this respect, those included in the study were all frail patients suffering from CRF and were undergoing HMV, thus with the common characteristic of a great burden of assistance. Another limitation of the study is the lack of any evaluation of patients' quality of life. This was mainly due to the difficulty of using standardised questionnaires for CRF patients on LTOT and/or mechanical ventilation. In spite of these limitations, the current authors believe that these preliminary data confirm the feasibility and efficacy of a TA project $[29,30]$ for management of advanced stages of CRF patients.

In conclusion, the present study demonstrates that, in severe and frail chronic respiratory failure patients needing home oxygen therapy and/or mechanical ventilation, a nurse-centred tele-assistance programme (supported by the continuous availability of a 24-h call centre and pulse oxygen device) is effective in preventing hospitalisations, home acute exacerbations and urgent general practitioner calls, and may be cost-effective. The chronic obstructive pulmonary disease group seems to take greater advantage from such a programme of tele-assistance.

\section{APPENDIX 1: RESPICARD}

Name $\mathrm{O}_{2}\left(\mathrm{~L} \cdot \min ^{-1}\right):$ age Rest MV: after effort date time tracheostomy: during exacerbation

\section{ACKNOWLEDGEMENTS}

The authors would like to thank R. Allpress (Fondazione S. Maugeri IRCCS, Pavia, Italy) for careful linguistic revision of the manuscript, in addition to all members of the telemedicine medical staff of the Fondazione S. Maugeri IRCCS, Lumezzane, Italy (E. Bertella, S. Gilè, L. Barbano, R. Porta and D. Fiorenza), telemedicine nursing staff from the Servizio di Telemedicina, Fondazione S. Maugeri IRCCS, Lumezzane (G. Assoni, L. Marchina, P. Pizzocaro, C. Giudici and P. Pedersoli) and F. Glisenti and his HTN call centre team (Brescia, Italy) for their valued and generous contribution.

\section{REFERENCES}

1 American Thoracic Society. Statement on home care for patients with respiratory disorders. Am J Respir Crit Care Med 2005; 171: 1443-1464.

2 Lloyd-Owen SJ, Donaldson GC, Ambrosino N, et al. Patterns of home mechanical ventilation use in Europe: results from the Eurovent survey. Eur Respir J 2005; 25: 1025-1031.

3 Report of a Consensus Conference of the American College of Chest Physicians. Mechanical ventilation beyond the intensive care unit. Chest 1998; 113: Suppl. 5, 289S-344S.

4 Farre R, Lloyd-Owen SJ, Ambrosino N, et al. Quality control of equipment in home mechanical ventilation: a European survey. Eur Respir J 2005; 26: 86-94.

\section{TABLE}

\section{Respicard questions}

\begin{tabular}{|c|c|c|c|c|c|}
\hline Score & 0 & 1 & 2 & 3 & 4 \\
\hline $\mathrm{Sp}, \mathrm{O}_{2}$ & $\begin{array}{c}>92 \% \text { with room air } \\
\text { and } \mathrm{O}_{2}\end{array}$ & $\begin{array}{l}91 \% \text { with air and } \\
90-92 \% \text { with } \mathrm{O}_{2}\end{array}$ & $<90 \%$ with room air & $<90 \%$ with $\mathrm{O}_{2}$ & $<80 \%$ with $\mathrm{O}_{2}$ \\
\hline Heart rate beats $\cdot \min ^{-1}$ & $<90$ & $90-100$ & $100-110$ & $110-120$ & $>120$ \\
\hline Dyspnoea & Under strong activity & Speed walk or climb & $\begin{array}{l}\text { Moderate activity } \\
\text { with stops }\end{array}$ & $\begin{array}{l}\text { Light activity, stop } \\
\text { after few steps }\end{array}$ & $\begin{array}{l}\text { At rest during daily } \\
\text { activities }\end{array}$ \\
\hline Cough & Spontaneous and strong & Weak, not productive & $\begin{array}{l}\text { Strong but extremely } \\
\text { productive }\end{array}$ & $\begin{array}{l}\text { Weak, productive, } \\
\text { frequent }\end{array}$ & $\begin{array}{l}\text { No spontaneous cough; } \\
\text { need for suctions }\end{array}$ \\
\hline Sputum & No need for sputum & Moderate & Copious & Very copious & Unbearable \\
\hline Sputum colour & No sputum & White & Yellow & Yellow/green & Green/brown or with blood \\
\hline Wheeze & Never & Occasional & Under strong efforts & Under moderate efforts & At rest \\
\hline Weight/ankle oedema & $\begin{array}{l}\text { Stable weight, } \\
\text { no ankle oedema }\end{array}$ & $\begin{array}{c}\text { Increase of }<2 \mathrm{~kg} \\
\text { in } 2 \text { days }\end{array}$ & $2-4 \mathrm{~kg}$ in 2 days & $2-4$ in 1 day & $>4 \mathrm{~kg}$ in 1 day \\
\hline Temperature & Normal & $\begin{array}{c}>37^{\circ} \mathrm{C} \text { and }<37.5^{\circ} \mathrm{C} \\
\text { without antipiretic }\end{array}$ & $\begin{array}{c}>37^{\circ} \mathrm{C} \text { and }<38^{\circ} \mathrm{C} \\
\text { with antipiretic }\end{array}$ & $\begin{array}{l}>38^{\circ} \mathrm{C} \text { with antipiretic } \\
\text { and antibiotic for } 1 \text { day }\end{array}$ & $\begin{array}{c}>38^{\circ} \mathrm{C} \text { with antibiotic } \\
\text { for } 3 \text { days }\end{array}$ \\
\hline Neurological status & Normal, wakeful & Slow but answering & $\begin{array}{l}\text { Confused, diurnal } \\
\text { drowsiness }\end{array}$ & $\begin{array}{l}\text { Difficult posture and } \\
\text { verbal answer }\end{array}$ & $\begin{array}{l}\text { No answer to } \\
\text { manual stimulus }\end{array}$ \\
\hline Ventilator interaction & $\begin{array}{l}\text { No troubles or } \\
\text { no ventilator }\end{array}$ & $\begin{array}{l}\text { Occasional alarms } \\
\text { on ventilator }\end{array}$ & $\begin{array}{l}\text { Alarms and need for } \\
\text { suction, or mask } \\
\text { discomfort }\end{array}$ & $\begin{array}{c}\text { Alarms, occasional } \\
\text { contrasts and dyspnoea } \\
\text { under ventilator }\end{array}$ & $\begin{array}{c}\text { Ventilator break; alarms } \\
\text { and fighting against } \\
\text { ventilator }\end{array}$ \\
\hline Walk & Autonomous & $\begin{array}{c}\text { Walk with stops, } \\
\text { no dyspnoea }\end{array}$ & $\begin{array}{l}\text { Walk with stick } \\
\text { and dyspnoea }\end{array}$ & $\begin{array}{l}\text { Assisted walk, few } \\
\text { steps, armchair use }\end{array}$ & $\begin{array}{l}\text { No deambulation, } \\
\text { bedridden }\end{array}$ \\
\hline \multicolumn{6}{|l|}{ Sum } \\
\hline Total sum & & & & & \\
\hline
\end{tabular}

Score Legend: normality (green zone; score 0-5); moderately pathological condition (yellow zone; score 6-12: caution; score 13-36: alarm zone); extremely severe condition (red zone; score $36-48$ ). $\mathrm{Sp}, \mathrm{O}_{2}$ : arterial oxygen saturation measured by pulse oximetry. 
5 ATS Consensus Statement.: Care of the child with a chronic tracheostomy. Am J Respir Crit Care Med 2000; 161: 297-308.

6 Vitacca M, Escarrabill J, Galavotti G, et al. Home mechanical ventilation patients: a retrospective survey to identify level of burden in real life. Monaldi Arch Chest Dis 2007; 67: 142-147.

7 Mannino DM, Watt G, Hole D, et al. The natural history of chronic obstructive pulmonary disease. Eur Respir J 2006; 27: 627-643.

8 Celli BR, Barnes PJ. Exacerbations of chronic obstructive pulmonary disease. Eur Respir J 2007; 29: 1224-1238.

9 Hilleman DE, Dewan N, Malesker M, Friedman M. Pharmacoeconomic evaluation of COPD. Chest 2000; 118 : 1278-1285.

10 Bourbeau J, Julien M, Maltais F, et al. Reduction of hospital utilization in patients with chronic obstructive pulmonary disease: a disease-specific self-management intervention. Arch Intern Med 2003; 163: 585-591.

$11 \mathrm{Wu}$ JYF, Leung WYS, Chang S, et al. Effectiveness of telephone counselling by a pharmacist in reducing mortality in patients receiving polypharmacy: randomized controlled trial. BMJ 2006; 333: 522.

12 Hermiz O, Comino E, Marks G, Daffurn K, Wilson S, Harris M. Randomised controlled trial of home based care of patients with chronic obstructive pulmonary disease. BMJ 2002; 325: 938.

13 Casas A, Troosters T, Garcia-Aymerich J, et al. Integrated care prevents hospitalizations for exacerbations in COPD patients. Eur Respir J 2006; 28: 123-130.

14 Adams SG, Smith PK, Allan PF, Anzueto A, Pugh JA, Cornell JE. Systematic review of the chronic care model in chronic obstructive pulmonary disease prevention and management. Arch Intern Med 2007; 167: 551-561.

15 Murray CJ, Lopez AD. Alternative projections of mortality and disability by cause 1990-2020: Global Burden of Disease Study. Lancet 1997; 349: 1498-504.

16 Grasso ME, Weller WE, Shaffer TJ, Diette GB, Anderson GF. Capitation, managed care, and chronic obstructive pulmonary disease. Am J Respir Crit Care Med 1998; 158: 133-138.

17 Mapel DW, Hurley JS, Frost FJ, Petersen HV, Picchi MA, Coultas DB. Health care utilization in chronic obstructive pulmonary disease. A case-control study in a health maintenance organization. Arch Intern Med 2000; 160: 2653-2658.
18 Hensher M, Fulop N, Coast J, Jefferys E. The hospital of the future. Better out than in? Alternatives to acute hospital care. BMJ 1999; 319: 1127-1130.

19 Cockcroft A, Bagnall P, Heslop A, et al. Controlled trial of respiratory health worker visiting patients with chronic respiratory disability. BMJ 1987; 294: 225-228.

20 Young M, Sparrow D, Gottlieb D, Selim A, Friedman R. A telephone-linked computer system for COPD care. Chest 2001; 119: 1565-1575.

21 Agha Z, Schapira RM, Maker AH. Cost effectiveness of telemedicine for the delivery of outpatient pulmonary care to a rural population. Telemed J E Health 2002; 8: 281-291.

22 Vitacca M, Pizzocaro P, Assoni G, et al. A pilot study of nurse-led, home-based TP for 45 patients with chronic respiratory insufficiency with mechanical ventilation assistance. J Telemed Telecare 2006; 12: 337-342.

23 Vitacca M, Assoni G, Guerra A, et al. Telesorveglianza durante un episodio di riacutizzazione di BPCO. [Telesurveillance during an episode of COPD relapse]. Rassegna Patologia App Respiratorio 2006; 21: 46-54.

24 Katz, S., Ford AB, Moskowitz RW, Jackson BA, Jaffe MW., Studies of illness in the aged-the index of ADL: a standardized measure of biological and psychosocial function. JAMA 1963; 185: 914-919.

25 Giordano A, Scalvini S, Zanelli E, et al. Multicenter randomised trial on home based telemanagement to prevent hospital readmission of patients with chronic heart failure. Int J Cardiol 2008; Epub ahead of print [PMID: 18222552].

26 Maiolo C, Mohamed EI, Fiorani CM, De Lorenzo A. Home telemonitoring for patients with severe respiratory illnesses: the Italian experience. J Telemed Telecare 2003; 9: 67-71.

27 Vontetsianos T, Giovas P, Katsaras T, et al. Telemedicineassisted home support for patients with advanced chronic obstructive pulmonary disease: preliminary results after nine-month follow-up. J Telemed Telecare 2005; 11: Suppl. 1, S86-S88.

28 Riegel B, Carlson B, Kopp Z, Le Petri B, Glaser D, Unger A. Effect of a standardised nurse case-management telephone intervention on resource use in patients with chronic heart failure. Arch Intern Med 2002; 162: 705-712.

29 Scalvini S, Zanelli E, Volterrani M, et al. A pilot study of nurse-led, home-based telecardiology for chronic heart failure patients. J Telemed Telecare 2004; 10: 113-117.

30 Hailay D, Roine R, Ohinmaa A. Systematic review of evidence for the benefits of telemedicine. J Telemed Telecare 2002; 8: Suppl. 1, 1-7. 